\title{
Mechanizing Chile Peppers: Challenges and Advances in Transitioning Harvest of New Mexico's Signature Crop
}

\author{
Stephanie J. Walker ${ }^{1,3}$ and Paul A. Funk ${ }^{2}$
}

AdDitional Index words. Bracero Program, Capsicum annuum, destemming, mechanical harvest, North American Free Trade Agreement

\begin{abstract}
Summary. New Mexican-type red and green chile (Capsicum annuum) is important to New Mexico's identity and economy. Producers began experimenting with mechanical harvest in the mid-1960s, but efforts stalled in the 1970s. Adverse impact to production following the implementation of the North American Free Trade Agreement spurred renewed interest in chile mechanization. Through private and public collaboration, the red chile industry in New Mexico has successfully transitioned with more than $80 \%$ of domestic acreage currently mechanized. Green chile has proven to be more challenging with fruit damage and lack of efficient mechanical stem removal posing key obstacles. Recent identification and developments in equipment have provided necessary components for mechanization of green chile, but must be scaled-up to production volumes.
\end{abstract}

$\mathrm{N}$ ew Mexican-type chile, often referred to as "Anaheim," is recognized as New Mexico's signature crop. Both the red and green (fully sized, but physiologically immature) crops are celebrated in local cuisine, culture, and art. Further, the production and processing of chile is an integral contributor to the state's economy (Hall and Skaggs, 2003). The first New Mexican-type chile, 'New Mexico No. 9', was officially released in 1921 from the New Mexico College of Agriculture and Mechanical Arts [now New Mexico State University (NMSU)]. Fabian Garcia, the first head of the college's agriculture experiment station, developed the cultivar through selective breeding for smooth skin, consistent heat level, and uniform fruit size. 'New Mexico No. 9' was a cultivar

\footnotetext{
This paper was part of the colloquium "Strategy for Developing Mechanical Harvesting of Horticultural Crops: Simultaneous Short-, Medium-, and Longterm Strategies" held 24 July 2013 at the ASHS Annual Conference, Palm Desert, California, and sponsored by the Production and Harvest Mechanization $(\mathrm{MECH})$ Working Group.

Support for chile pepper mechanization research has been provided by the New Mexico Chile Task Force, the New Mexico Chile Association, the New Mexico Chile Commission, Hatch funds, and the New Mexico State University Agriculture Experiment Station.
}

${ }^{1}$ Department of Extension Plant Sciences, New Mexico State University, 945 College Drive, PO Box 30003 , Las Cruces, NM 88003

${ }^{2}$ USDA Agricultural Research Service, Southwestern Cotton Ginning Research Laboratory, 300 East College Drive, PO Box 578, Mesilla Park, NM 88047

${ }^{3}$ Corresponding author. E-mail: swalker@nmsu.edu. suitable for canning and was acceptable to a wide base of consumers, and thereby was integral to the launch of commercial chile production in New Mexico and surrounding states (Bosland, 1992).

New Mexico's official state question, "Red or green?," (State of New Mexico, 2005) refers to an individual's preference for red or green chile recipes when ordering a meal. Red fruit are simply physiologically mature green fruit; however, New Mexican-type red chile and green chile are grown, harvested, processed, and sold in very distinctive manners. In the early days of commercial processing, a chile crop would first be harvested for a green crop. Late setting fruit would be left on the plant until red ripe, and then harvested as a red crop. As the industries matured, cultivars were developed that possessed characteristics specifically for either green chile or red chile use. Preferably, green chile fruit are thick walled and 15 to $18 \mathrm{~cm}$ in length to provide high-quality processed whole green chile. In contrast, red chile processors favor fruit with thinner walls for more efficient drying. In addition, low heat level (<700 Scoville heat units) or no heat, and high-pigmentation are desirable quality attributes in red chile
(Bosland and Walker, 2004). The level of pigmentation, or extractable color, is measured through a spectrophotometric method developed by the American Spice Trade Association (ASTA, 1985) and reported in ASTA color units. A red chile sample with 180 ASTA would exhibit a richer red color in the finished product compared with a sample with an 80 ASTA measurement (Bosland and Votava, 2012).

Before the late 1980s, both the red and green chile crops were handharvested in New Mexico. The Bracero Program, initially created to bring temporary farm workers to the United States from Mexico to alleviate labor shortages during World War II, was initiated in 1942. During this period, many growers in New Mexico participated in the program to obtain the workforce needed to maintain and harvest their labor-intensive chile crops. Following the termination of the Bracero Program in 1964, chile producers and processors intensified efforts to mechanize field operations. The first documented trial of mechanical chile harvest was carried out in 1965 by Ernest Riggs in Las Cruces, NM. In that case, a mechanism fitted with inclined, counterrotating brushes was propelled through the rows of chile plants to dislodge the fruit (Marshall, 1994; Marshall and Boese, 1998). That test was followed by a number of additional trials performed by chile growers, processors, and small-scale equipment manufacturers who implemented their own designs or improvements on subsequent designs to strive for more efficient mechanical harvest. Wondel Creagar, who was awarded the first patent on a mechanical chile harvester in 1971, developed a picking head comprised of eight vertical, counterrotating helixes with four positioned on each side of the plant row (Marshall and Boese, 1998) (Fig. 1). Today, machines fitted with counterrotating helixes are the predominant red chile pickers in use (Walker, 2009). However, other designs that employ a series of fingers or belts that comb through the plants to remove the chile fruit are also employed (Funk and Marshall,

\begin{tabular}{llll}
\hline $\begin{array}{l}\text { Units } \\
\begin{array}{l}\text { To convert U.S. to SI, } \\
\text { multiply by }\end{array}\end{array}$ & U.S. unit & SI unit & $\begin{array}{l}\text { To convert SI to U.S., } \\
\text { multiply by }\end{array}$ \\
\hline 0.4047 & acre $(\mathrm{s})$ & ha & 2.4711 \\
2.54 & inch(es) & cm & 0.3937
\end{tabular}


2012). Researchers at NMSU were also engaged in mechanical harvest research following the termination of the Bracero Program. In 1979, Roy Nakayama, the chile breeder at NMSU, received a mechanical chile harvester from Santa Maria Chile, Inc. [Santa Maria, CA (currently Mölndal, Sweden)] to aid in the school's mechanical harvest research. The machine's picking head was developed by George Abernathy, an Agricultural Engineer at NMSU (G. Abernathy, personal communication). However, in the years following the 1978 lawsuit against the University of California that restricted federal funding on any research that could reduce the need for hand laborers, research in chile mechanization at NMSU essentially stopped. This mirrored actions taken by other public institutions across the United States during that time (Peterson, 2005; Sarig et al., 2000).

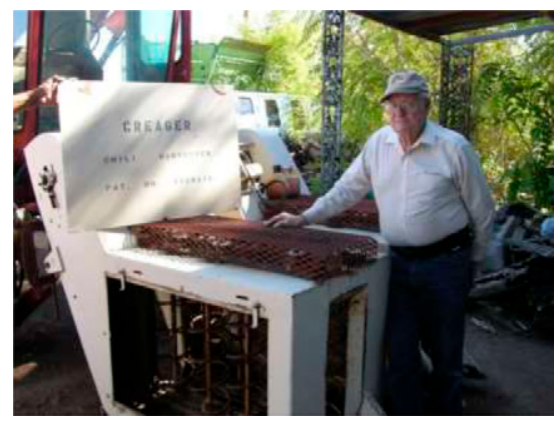

Fig. 1. Wondel Creager pictured in 2003 with one of the first available mechanical harvesters he developed in the early 1970s for red chile harvest. The picking mechanism consists of eight vertical, counterrotating helixes with four positioned on each side of the chile plant row.

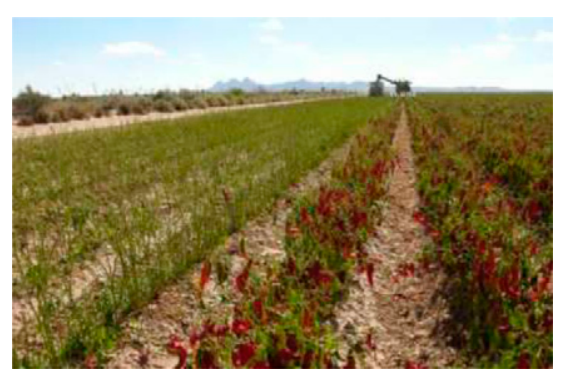

Fig. 2. Mechanical harvest of a commercial red chile field in Deming, $\mathrm{NM}$, in 2004. Close plant spacing [ $>40,000$ plants/acre $(98,842.1$

plants/ha)] and defoliation contribute to optimum conditions for mechanical harvest of red chile fields.
Consumption of chile in the United States has steadily increased since the 1980s. Initially, this increase in demand mirrored an increase in production in New Mexico. Chile acreage in New Mexico peaked in 1992 when more than 34,000 acres were harvested (Hall and Skaggs, 2003). The implementation of the North American Free Trade Agreement in 1994 had an immediate impact on chile acreage in New Mexico. Even as overall consumption continued to increase, production of chile in New Mexico decreased to a post-peak low of 8700 acres harvested in 2010 (New Mexico Department of Agriculture, 2010). Conversely, the volume of imported chile steadily increased to fill the rising domestic demand (Gandonou and Waliczek, 2013; Lucier and Dettmann, 2008). New Mexican chile producers recognized the precarious position of the industry in the state and approached NMSU for assistance. In 1998, the New Mexico Chile Task Force (transformed into the New Mexico Chile Association in 2007) was formed to unite industry and researchers from the university and the U.S. Department of Agriculture-Agricultural Research Service (USDA-ARS) Cotton Ginning Research Laboratory (Las Cruces, NM) in efforts to reverse the downward trend (Diemer et al., 2002). Costs associated with hand harvesting account for $\approx 50 \%$ of the overall production expenditures. In comparison, operations that have transitioned to mechanical harvest spend less than $10 \%$ on labor (Eastman et al., 1997). As a result, adoption of mechanical harvest is a critical method to make New Mexico-grown chile more competitive with imported product. Therefore, mechanization was one of the key areas focused on by the New Mexico Chile Task Force.

Supported by the collaborative effort between private and public research, the red chile industry in New Mexico has been highly successful in their transition to mechanization. Before the 1990s, red chile was completely hand-harvested. Today, more than $80 \%$ of the acreage is mechanically harvested (Bosland and Walker, 2004) (Fig. 2). Red chile mechanical harvest trials showed that fields containing tall plants with narrow branch angles, and a fruit set off the ground and well dispersed through the plant canopy provided for an optimum harvest (Wall et al., 2003). In 2004, 'NuMex Garnet' was the first chile cultivar released by NMSU that was specifically evaluated for mechanical harvest traits (Walker et al., 2004). Breeding efforts to develop cultivars possessing these traits is ongoing. Crop management techniques are also critical to create plant and field conditions that optimize mechanical harvest. Closer plant spacing, for example, contributes to a more efficient mechanical harvest by increasing the height of the lowest fruit above the ground. Accordingly, the mechanical picking heads can more easily harvest the fruit. Populations of 40,000 plants/acre are optimum, but more than 80,000 plants/acre causes lower yields because of excessive crowding (Paroissien and Flynn, 2004). Methods to expedite plant senescence near the end of the growing season, such as application of sodium chlorate to defoliate plants, are also employed and provide for a cleaner, more efficient mechanical harvest of red chile (Walker, 2009).

Red chile is typically harvested late in the season when fruit are partially dry. Since the processed product is usually ground, some damage to the fruit during harvest does not significantly affect quality. While the red chile industry has predominantly transitioned to mechanical harvest, the easily damaged New Mexican-type green chile crop is entirely hand-harvested. Mechanical harvest of green chile has proven to be particularly challenging. The key obstacles are unacceptability of damaged fruit (Funk et al., 2011) and the need for a mechanical means of stem removal from the fruit (Herbon et al., 2009). Collaborative research between NMSU and the USDA-ARS Cotton Ginning Research Laboratory identified an inclined double helix picking head manufactured by Yung-Etgar (Bet-LehemHglilit, Israel) as being most the most gentle fruit harvest mechanism (Fig. 3) of those tested to date. Several experimental and commercial picking heads were tested and the Yung-Etgar picking head had the lowest average of $11 \%$ damaged fruit (Funk and Walker, 2010). At the same time, differences were observed in mechanical harvest efficiency of different New Mexicantype green chile cultivars. Significant cultivar differences were measured in weight of sticks and stems, broken fruit, and fruit left in the field after 
mechanical harvesting trials performed at the Leyendecker Plant Science Research Center (Las Cruces, NM) in 2009 and 2010 (unpublished data) (Fig. 4). Of the green chile cultivars tested, PHB-109 and Despanado (Curry Chile and Seed Co., Pearce, AZ) proved to be the most amenable to mechanical harvest (Walker and Funk, 2010).

Currently, efforts continue to develop a machine that will efficiently remove stems (calyx and pedicel) from green chile fruit (Herbon et al., 2009). Stem removal

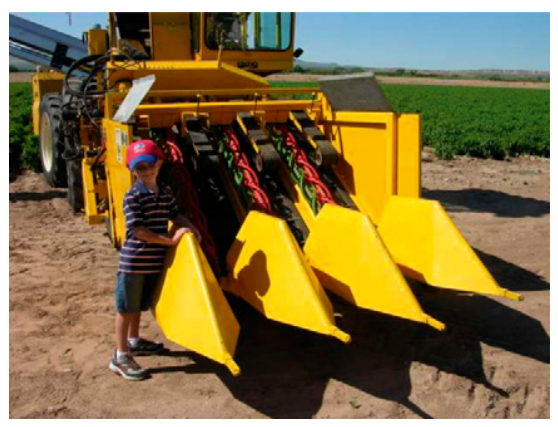

Fig. 3. Chile harvester manufactured by Yung-Etgar (Bet-Lehem-Hglilit, Israel) pictured in 2009 before use in a green chile mechanical harvest demonstration in a commercial field in Salem, NM. The picking head consists of three pairs of inclined, opposite-rotating double helices that detach the fruit from the plants. The harvester is attached to a power and propulsion unit provided by Oxbo International Corp. (Clear Lake, WI).

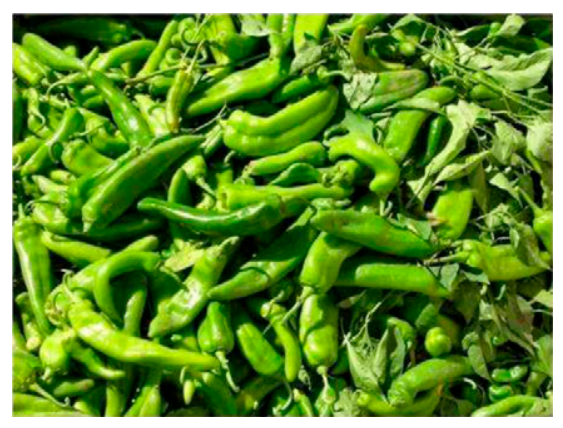

Fig. 4. Mechanically harvested green chile [cultivar Despanado (Curry Chile and Seed Co., Pearce, AZ)] picked with the Yung-Etgar harvester (Bet-Lehem-Hglilit, Israel) from cultivar trials at New Mexico State University's Leyendecker Plant Science Research Center near Las Cruces, NM in 2009. is achieved by mechanically cutting the top off of the fruit or by pinching the stem off of the fruit in a manner similar to that of handdestemming. Promising mechanical destemmers representing both options have been developed and are close to realization through both public sector and private manufacturers.

The red chile industry in New Mexico has predominately transitioned to mechanical harvest. This shift has positioned the industry to be internationally competitive. Currently, the components necessary to implement mechanical harvest of green chile in New Mexico are available but must be scaled-up to production volumes. Finally, as with all business ventures, economics drive the chile industries in New Mexico. The availability of hand labor in the state will ultimately impact adoption. Full transition to mechanical harvest of green chile will occur when mechanically harvested chile provides quality and profitability equal or greater than what is currently provided by hand-harvested product. To achieve this outcome, a system must be in place where researchers, growers, and processors cooperate to optimize cultivars, field conditions, and machinery.

\section{Literature cited}

American Spice Trade Association. 1985. Official analytical methods. 3rd ed. Amer. Spice Trade Assn. Englewood Cliffs, NJ.

Bosland, P.W. 1992. Chiles: A diverse crop. HortTechnology 2:6-11.

Bosland, P.W. and E.J. Votava. 2012. Peppers: Vegetable and spice capsicums. 2nd ed. CABI, Cambridge, MA.

Bosland, P.W. and S. Walker. 2004. Growing chiles in New Mexico. New Mexico State Univ. Coop. Ext. Serv. Guide H-230.

Diemer, J.A., R. Phillips, and M. Hillon. 2002. An industry-university response to global competition. New Mexico State Univ. Chile Task Force Rpt. 1.

Eastman, C., F. McClellan, and T. Bagwell. 1997. Impact of increasing wages on New Mexico chile production. New Mexico State Univ. Agr. Expt. Sta. Res. Rpt. No. 714.
Funk, P.A. and D.E. Marshall. 2012. Peppers: Botany, production and uses. CAB Intl., Wallingford, U.K.

Funk, P.A. and S.J. Walker. 2010. Evaluation of five green chile cultivars utilizing five different harvest mechanisms. Appl. Eng. Agr. 26:955-964.

Funk, P.A., S.J. Walker, and R.P. Herbon. 2011. A systems approach to chile harvest mechanization. Intl. J. Veg. Sci. 17:296309.

Gandonou, J.M. and T.M. Waliczek. 2013. An analysis of the recent trends in U.S. chile pepper production, consumption and imports. J. Food, Agr. Environ. 11:361-367.

Hall, T.Y. and R.K. Skaggs. 2003. Economic impact of southern New Mexico vegetable production and processing. New Mexico State Univ. Chile Task Force Rpt. 9.

Herbon, R., D. Cillessen, E. Gamillo, and A. Hyde. 2009. Engineering a machine to remove stems from chile peppers - A critical need for the New Mexico chile industry. Proc. Amer. Soc. Agr. Biol. Eng. Paper No. 095710.

Lucier, G. and R.L. Dettmann. 2008. Vegetables, fresh market: U.S. imports of major vegetables, 1979-2007. In: Vegetables and melons situation and outlook yearbook. US. Dept. Agr., Washington, DC.

Marshall, D.E. 1994. Status of mechanical pepper harvesting. Proc. Amer. Soc. Agr. Biol. Eng. Paper No. 941578.

Marshall, D.E. and B.N. Boese. 1998. Breeding Capsicum for mechanical harvest. Proc. 10th Eucarpia Mtg. Genet. Breeding Capsicum Eggplant 10:6164.

New Mexico Department of Agriculture. 2010. New Mexico agricultural statistics. New Mexico Dept. Agr., Las Cruces, NM.

Paroissien, M. and R. Flynn. 2004. Plant spacing/plant population for machine harvest. New Mexico Chile Task Force Rpt. 13. New Mexico State University, Las Cruces, NM.

Peterson, D.L. 2005. Harvest mechanization progress and prospects for fresh market quality deciduous tree fruits. HortTechnology 15:72-75.

Sarig, Y., J.F. Thompson, and G.K. Brown. 2000. Alternatives to immigrant labor? The status of fruit and vegetable harvest mechanization in the United States. 10 May 2013. <http:// www.cis.org/articles/2000/back1200. html>. 


\section{Colloquium}

State of New Mexico. 2005. New Mexico State Legislature handbook. 10 May 2013. <http://www.nmlegis.gov/lcs/ lcsdocs/nmleghandbook01-05.pdf/>.

Walker, S. and P.A. Funk. 2010. Mechanical harvest trials of New Mexican-type green chile (Capsicum annuum L.). HortScience 45:145-146. (abstr.).
Walker, S.J. 2009. Red chile and paprika production in New Mexico. New Mexico State Univ. Coop. Ext. Serv. Guide H257.

Walker, S.J., M.M. Wall, and P.W. Bosland. 2004. 'NuMex Garnet' paprika. HortScience 39:629-630.
Wall, M.M., S.J. Walker, A.D. Wall, S.E. Hughs, and R. Phillips. 2003. Yield and quality of machine-harvested red chile peppers. HortTechnology 13:296302. 